\section{Reply to Castellani: strategic conservation interventions on the Agulhas Plain}

The comment by Carlo Castellani [Oryx, 34(1), 3-7] to our paper (Heydenrych et al., 1999) begs a response. Clearly the author did not comprehend fully the content of our paper.

The main concern raised by Castellani was that 'the only strategy that was considered for saving the fynbos ecosystem was purchasing land and gazetting it as a protected area'. On the contrary, the paper lists a range of actions for achieving conservation targets that explicitly do not require the purchase of land by the state (Heydenrych et al., 1999; Table 1). Furthermore, two such actions, contractual national parks and conservancies, both involving state-private sector partnerships, are discussed in some detail.

We are acutely aware that like most countries of the world, South Africa cannot afford to purchase as statutory reserves all of the land that it requires to achieve conservation targets. This is especially true of lowland areas, such as the Agulhas Plain, where many forms of land use compete with conservation. However, we do advocate that the core $(12,000 \mathrm{ha})$ of the proposed 20,000 ha Agulhas National Park should enjoy strict reservation in state-owned land. This is the minimum area required to ensure the persistence of the region's uniquely diverse biodiversity, as well as the processes that maintain and generate this biodiversity. There is an increasing acceptance that strict reservation in defensible protected areas is a strategy essential for minimizing the loss of biodiversity in species-rich areas, which are vulnerable to threatening processes (van Schaik \& Kramer, 1997).

The remainder of the Agulhas National Park will remain under private ownership, where land will be incorporated into the park on a contractual basis after negotiating agreements that provide benefits to both the state and to the private sector. It is intended that areas of natural habitat, which have not been identified as essential for achieving reservation targets, should ultimately be subject to some form of off-reserve conservation. A project-funded by the Global Environmental Facility - is currently investigating a wide range of instruments to do this. Our paper suggests a biosphere reserve model to provide the framework for co-ordinating these actions.

Overall, we recommend that 8 per cent of the Agulhas Plain, an area of some $1500 \mathrm{sq} \mathrm{km}$, which is home to about 100 endemic plant species and many other unique biodiversity features, be subject to strict reservation. In parts of Europe, where the maintenance of certain agricultural practices is an important component of biodiversity conservation, conflicts between human use and preservation may be considerably less than in the Cape fynbos region, of which the Agulhas Plain is part. Given that other forms of land use, including 'sustainable' wildflower harvesting, pose a major threat to the region's biodiversity (Heydenrych, unpublished data), we consider strict reservation as one of several actions required for the long-term conservation of the Agulhas Plain's biodiversity.

\section{Barry Heydenrych}

South African National Parks

PO Box 55, Stanford 7210

South Africa

E-mail: BarryH@parks-sa.co.za

Richard Cowling

Institute for Plant Conservation

University of Cape Town, Private Bag

Rondebosch 7701, South Africa

\section{References}

Heydenrych, B.J., Cowling, R.M. \& Lombard, A.T. (1999) Strategic conservation interventions in a region of high biodiversity and a high vulnerability: a case study from the Agulhas Plain at the southern tip of Africa. Oryx, 33(3), $256-269$.

van Schaik, C.P. \& Kramer, R.A. (1997) Towards a new protection paradigm. In Last Stand. Protected Areas and the Defence of Tropical Biodiversity (eds R. A. Kramer, C. P. van Schaik and J. Johnson), pp. 212-230. Oxford University Press, New York. 